\title{
Nursing as a Profession beyond Tropes of the Image among Public, Media, and the Identity Crisis: A Discussion Paper
}

\author{
Mahendra Kumar \\ Stroke Team Coordinator, Post Graduate Institute of Medical Education and Research, Chandigarh, UT
}

\begin{abstract}
The image of nursing is impoverished since the hundred years of professional identity of this age-old profession. Nursing image among the public is relying on the image of nursing in media. Nurses are vital members of the health care team and work tirelessly to provide quality care to the patient. A professional image is pivotal to motivate people to have nursing as a career choice. Nurses are central resources of any health institution and their role as a carer is crucial to push the quality of care and health outcomes of health services. Nurses are known to work with compassion and competence with the patient's best interest in mind having good academic knowledge and understanding of their work with evidence-based practice. Nurses facing an identity crisis as professional and likely sources are neglecting behavior of media and public image of nursing as assistant of physicians. The nursing profession is facing new challenges part from biased policies of the government, on the public forum as an independent professional.
\end{abstract}

Keywords: Nursing, Professionalism, Media, Society, Image, Physicians

\section{INTRODUCTION}

A professional image is a way a person appears to others, and it is part of a profession and the way that profession appears to other disciplines and the general public. ${ }^{1}$

In the increasingly diverse, twentyfirst century, nurses facing several complex challenges to creating a positive professional image. They often experience a significant incongruence between their desired professional image and their perceived professional image. In other words, nurses are not recognized in the manner they desire, even, their distasteful professional image may be more firmly associated with how their key constituents perceive them. The historical trajectory of the nursing profession is worthy to mention that the initial frame of recognition of nursing as an occupation of physician's assistant. Florence Nightingale the precursor of modern nursing was more focused on care and kindness with a dream to see nursing as an independent profession with efforts to keep scientific knowledge and technical skills. ${ }^{2}$

In a world where a shortage of nurses raising over two million nurses and health care institutions facing a dearth of nurse's professional image of the nursing profession is pivotal to motivate others to join the noble profession. Despite the impressive technical and research advancement in health care, nursing has not been able to grow equally as a profession. The nursing profession required well-trained and highly academic sound professionals but people assume nursing as a low-status profession that is subordinate to the work of physicians, does not require any good academic qualifications. ${ }^{3}$

An increasing number of nurses are participating in higher education courses like graduation, post-graduation, and increasing trend of Ph.D. in nursing but these degrees are even not matters of 
concern before the public who take nurses as servants in the healthcare delivery system. ${ }^{4}$ Perception of nurses as specialized only in personal care of a patient like bed bath, oral care, bed sheet change, taking blood pressure and assisting in feeding, such things promotes the false perceptional image of the profession. Stagnant carriers with no appraisal opportunities for nurses to get rewarded and appreciation are never given or considered for nurses. The common misconception about nurses is considered for basic care rather than patient treatment.

\section{Nurse's image in public}

Through the past years, the nursing image has changed a great deal and is controlled by how the public perceives this profession. Despite all facts that how nurses are keeping their patients ahead of their interest and providing the best possible care during all odds time, either in peace or disaster, but nurses have not considered an expert professional. ${ }^{4}$ The condition quite worsens in developing countries like India where nurses do not get the due attention, even several achievements of showing par excellence in patient care and professionalism; nurses are still struggling to get recognized as professional in society.

The feeling of being subordinate dominance strongly influenced the role development. The essence of nursing is not always clear to people throughout time, an image of nursing has evolved rapidly. ${ }^{1}$ Nurse are working in an extremely stressful work environment with a lack of professional autonomy. Due to this white face identity, people do not take nurses as leaders of an individual with impendent professional identity and leading to a shortage of nurses across the world. ${ }^{5}$

Now in the era of performancebased professionalism people are constantly observing nurse's behavior and forming theories about their competence, character, and commitment, which are rapidly disseminated throughout working.
According to Laura Morgan Roberts, a professional image is the set of qualities and characteristics that represent perceptions of competence and character as judged by your key constituents.

\section{Nursing as an Image of caring Profession \\ Caring and kindness have been part} of the nursing profession's identity. Nurses are tried to gain recognition for the importance of caring in society but forget that caring is undervalued. In any country, nurses are the foundation of their healthcare system but people assume their image typically based on personal experiences with nurses during their hospital visit or shared experiences of others. ${ }^{6}$ This leads to a narrow view of the nursing profession often based only on a brief personal experience and may not provide an accurate picture of the whole profession.

This is unlikely to find a chance for nurses to get an opportunity to express themselves and this has made it difficult for nurses to talk more about their profession.

\section{Leadership crisis}

Many nurses, who achieved higher academics and special training despite holding leadership, do not get the possibility to play a more critical role in developing the capacity and capability for professional advocacy.

Nurses need to acquire strong competencies and skills to associate with physicians and other professionals of the health care team to play a visible role in transforming healthcare and showing credibility in leadership. ${ }^{7}$ This is high time for nursing leaders to be increasingly visible and an active ingredient in multidisciplinary and inter-professional collaborative decision-making that is needed at a time of crisis.

\section{The external factors responsible for image building}

- Historical handmaiden role of nurses

- No direct role in organizational policymaking

- Perceived female leading profession 


\section{The internal factors responsible for image building \\ - Timidity \\ - Insecurity \\ - Sense of inferiority and subordinates \\ - No, define role \\ - Lack of professional confidence}

\section{Gender and nursing}

Influence of the traditional role of nurses as a guest in physician's world and assistant-based status continues to suffer from the professional status. The stereotypical image of nurses is viewing this profession as a part of the female sphere, especially in India, nursing is still believed to the female lead profession and remains predominantly feminine and caring that has a low social status and is discredited by society due to multiple myths about the educational status of nurses. ${ }^{8}$

Despite the rhetoric success story of the nursing profession exist over the past 2,000 years, it is only in the last 166 years that women have become the dominant figures within nursing, and while nursing historians would be the first to agree that men were present it is often forgotten, though not intentionally, that men have to lead the development of nursing practice. ${ }^{9}$ Men still constitute a very small percentage of the total number of RNs living and working in one of the most developed countries the United States.

In India many state and federal government agencies coming with new recruitment rules making it difficult for men to join the nursing profession or get a job as a nurse. Even the contributions of men to the development of nursing since the early centuries have not been recognized by society.

The recent amendment of new nurse recruitment rule 80:20 for AIIMS recruitment in 2019 has become a matter of debate in the country. According to the new recruitment CAT rule, only female participants can apply on $80 \%$ of seats in AIIMS nurses recruitment, and this further adds to the famine image of the nursing profession. $^{10}$

\section{Media and Nursing}

Media portraying nurses as subservient roles with low intellect with handful remuneration. The profession is facing extreme role reversal from physician's assistant to independent practitioner. A well-known journalist Suzanne Gordon from the USA has said that how nurses respond to these changes and communicated them to the people and other healthcare professionals represents a lot about their profession. Undoubtedly the media poorly respond to nurse's issues and their achievements. Many media professionals are not enough informed about their qualifications and role in patient care and portrait nurses as angels of mercy despite their technical and academic excellence and direct role in inpatient treatment.9,10 Nurses are not taken as a leader or key member of the healthcare team in media. Due to such images, the public does not find nurses as autonomous healthcare providers. It's very hard to find media coverage of nurse's interviews and taking their view or opinions seriously resulted in poor perception about nursing. Although the traditional role and practices of nurses are no longer in practice, they had a significant impact on the nursing profession and current practice. Nurses and physicians extremely contribute to patient care but often do not appreciate the role of each other. ${ }^{11}$

\section{The nursing professional current image result in}

- Serious shortages of nurses due to image crisis

- Lack of interest in nursing as a profession

- Job description stress occurs through a perceived mismatch between the public image of the profession and the accomplishment.

- Low visibility in policymaking and decision capacity 


\section{New script of Nursing}

Nowadays, nurses are playing a remarkable role in the treatment, research, and advancement of the medical profession. Nursing is an old profession although innovations and new technology is coming throughout history. As nowadays nurse's interest and involvement in research have moved towards the construction of its body of scientific knowledge, and research. ${ }^{12}$ The fields of nursing have grown substantially in more recent years, with new leadership positions, numerous management in-service educations, and their role refinement inpatient care.

\section{Why Nurses need to improve the professional image}

The loss of professional pride and self-esteem can also inspire a more serious professional problem. A weak professional image can realize nurses like victims and victims do not take control, or lead but rather see others in control, they abdicate responsibility. ${ }^{13}$ On every occasion a nurse introduce herself/ himself as a nurse to their family, friends, or in public, every time the nurse is representing the profession. This has an impact on the image of nursing. How to improve the image of nursing in public here a small description?

- People should be aware and informed about the academic and technical requirements of being a nurse and let them know about nursing research and quality up-gradation in the nursing profession.

- Media awareness, in turn, will have a positive effect on the public image of nursing and will empower nurses.

- The fairer image of the nursing profession can be experienced by the availability of higher academic opportunities and a challenging work environment that encourages nurses to stand up for themselves.

- There must be some strategic positions like case managers, clinical nurse educators, or coordinators to motivate people to join nursing and improve the visibility of the profession as nurses increasingly take on more and more roles, which will add to the positive profile of this great profession.

\section{Dependent to independent as a profession: A way forward}

The value of nurses by the public is quite the contrary. Now nursing profession under the impression young enthusiastic nurses changing the persona as when one person tells another that he or she is a nurse, the typical response comes as positive. The self-concept, self-esteem, and performance of the nurses are all influenced by their impression of the nursing profession's image.

Loss of professional identity loss of professional pride and self-esteem nurses feel like victims and victims do not take control, but rather see others in control; they abdicate responsibility.

It is not uncommon for a nurse to refuse to talk to the press because the nurse feels no need to do this or sometimes because of the fear of reprisal from the nurse's employer. When nurses do speak to the press, often when being praised for an action, they say, "Oh, I was just doing my job. Positive images towards the nursing profession may assemble progressive and more grounded relations with their patients, associates, and community as a whole. Every nursing personnel represents the profession every day at work conveyed through uniform, appearance, credential identification, how one communicates and introduces oneself, and how one performs and provides care. The choice to enter nursing, to stay in nursing, and to advance nursing, is probably the after-effect of nurses $^{\text {ee }}$ view of the image of their job.

\section{Acknowledgement: None}

Conflict of Interest: None

Source of Funding: None

Ethical Approval: Not Applicable 


\section{REFERENCES}

1. Hoeve Y, Jansen G, Roodbol P. The nursing profession: public image, self-concept and professional identity. A discussion paper. Journal of Advanced Nursing. 2013; 70 (2): 295-309.

2. McDonald L. Florence Nightingale a Hundred Years on: who she was and what she was not. Women's History Review. 2010; 19(5):721-740.

3. Nursing the image: media, culture and professional identity. Choice Reviews Online. 2001; 38(09):38-5049-38-5049.

4. Kershaw B. The Future of Nursing-Leading Change, Advancing Health Institute of Medicine of the National Academies (USA) The Future of Nursing-Leading Change, Advancing Health National Academies Press 620pp \$49.95/£34 9780309158237 9780309158237. Nursing Standard. 2011; 26(7):31-31.

5. Westman B, Ullgren $H$, Sharp $L$. Introducing a new role in cancer care, coordinating contact nurses: Patientreported evaluation. Annals of Oncology. 2018;29:viii685.

6. Evans R. The Nurse's Social Media Advantage-How Making Connections and Sharing Ideas Can Enhance Your Nursing Practice The Nurse's Social Media Advantage-How Making Connections and Sharing Ideas Can Enhance Your Nursing Practice. Nursing Standard. 2011;25(38):3131.

7. 14. Scully N. Leadership in nursing: The importance of recognising inherent values and attributes to secure a positive future for the profession. Collegian. 2015; 22(4):439444.

8. Willetts G, Clarke D. Constructing nurses' professional identity through social identity theory. International Journal of Nursing Practice. 2013; 20(2):164-169.

9. J McCartan P, Hargie O. Effects of nurses' sex-role orientation on positive and negative assertion. Nursing and Health Sciences. 2004;6(1):45-49.

10. Sharma SK, Thakur K, Peter PP. Status of nurses in India: Current situation analysis and strategies to improve. J Med Evid 2020; 1:147-52.

11. Mason D, Nixon L, Glickstein B, Han S, Westphaln K, Carter L. The Woodhull Study Revisited: Nurses' Representation in Health News Media 20 Years Later. Journal of Nursing Scholarship. 2018;50(6):695704.

12. Urquhart C, Currell R, Grant M, Hardiker $N$. Nursing record systems: effects on nursing practice and healthcare outcomes. Cochrane Database of Systematic Reviews. 2018.

13. Larson J, Brady M, Engelmann L, Perkins B, Shultz C. The Formation of Professional Identity in Nursing. Nursing Education Perspectives. 2013; 34(2):138.

How to cite this article: Kumar M. Nursing as a profession beyond tropes of the image among public, media, and the identity crisis: a discussion paper. International Journal of Science \& Healthcare Research. 2021; 6(2): 5357. DOI: https://doi.org/10.52403/ijshr. 20210411 